\title{
TEORIA QUÂNTICA, FÍSICA NUCLEAR E FILOSOFIA GREGA: ENSAIO SOBRE OS FÍSICOS FILÓSOFOS DO SÉCULO XX
}

\author{
Vinícius Carvalho da Silva ${ }^{1}$ \\ Universidade do Estado do Rio de Janeiro (UERJ) \\ Casa de Oswaldo Cruz - Fundação Oswaldo Cruz (COC-Fiocruz) \\ (D) https://orcid.org/0000-0002-1061-2727
}

\section{RESUMO:}

No início do século XX seria impensável, entre cientistas europeus, separar ciência natural e filosofia. Os físicos filósofos foram cientistas como Einstein, Bohr, Heisenberg, Schrödinger, dentre outros, que refundaram a física ao lançar as bases da mecânica quântica e da relatividade especial e geral. Neste artigo analisamos brevemente como alguns desses pensadores encararam as questões do valor da ciência, da relação entre ciência e filosofia, e da importância da filosofia grega para a física nuclear e a teoria quântica.

PALAVRAS CHAVE: Filosofia Grega; Física Nuclear; Teoria Quântica; Valores; Utilitarismo.

\section{QUANTUM THEORY, NUCLEAR PHYSICS AND GREEK PHILOSOPHY: A ESSAY ON THE PHYSICISTS PHILOSOPHERS OF THE TWENTIETH CENTURY}

\begin{abstract}
:
At the beginning of the twentieth century it would be unthinkable, among european scientists, to separate natural science and philosophy. Physicists-philosophers were scientists such as Einstein, Bohr, Heisenberg, Schrödinger, among others, who refounded physics by laying the foundations of quantum mechanics and special and general relativity. In this paper we briefly review how some of these thinkers have looked at the issues of the value of science, the relationship between science and philosophy, and the importance of Greek philosophy to nuclear physics and quantum theory.
\end{abstract}

KEYWORDS: Greek Philosophy; Nuclear Physics; Quantum Theory; Values; Utilitarianism.

\footnotetext{
${ }^{1}$ Doutorando e Mestre em Filosofia da Ciência e Teoria do Conhecimento (UERJ), Rio de Janeiro - Brasil. Mestrando em História da Ciência e da Saúde (COC-Fiocruz). Professor da Faculdade Messiânica e pesquisador do Instituto de Estudos Conceituais e Sociais de Ciência, Tecnologia e Sociedade (IECTS). viniciusphilo.uerj@gmail.com

Teoria quântica, física nuclear e filosofia grega: ensaio sobre os físicos filósofos do século XX - Vinícius Carvalho da Silva
}

Griot : Revista de Filosofia, Amargosa, Bahia - Brasil, v.15, n.1, p.233-250, junho/2017

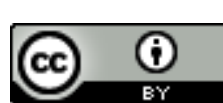




\section{Introdução}

Notamos, entre físicos e filósofos, pelo menos duas concepções divergentes acerca da relação entre filosofia e ciência. Há aqueles que simplesmente ignoram tal interação, não a considerando relevante, e os que a defendem como sendo fundamental. Qual será a posição de físicos filósofos como Heisenberg e Schrödinger e por que a consideramos a mais acertada? Para estes cientistas, filosofia e ciência são indissociáveis. Uma vez em que somos cientistas, a questão não é se faremos filosofia, mas como e com quais implicações a faremos. A ciência levanta problemas filosóficos, de epistemologia, ontologia, lógica, ética. Ignorar tais dimensões da pesquisa científica é desconhecer parte fundamental da própria ciência. Em sentido mais forte, a ciência $e ́$ um problema filosófico. Deste modo, quando fazemos uma pergunta do tipo: "Por que não podemos conhecer o momentum e a posição de um elétron, ao mesmo tempo?", ou, "como unificar mecânica quântica e relatividade?" desejamos entender o mundo, compreender a natureza. $\mathrm{O}$ que nos move agora não pode ser algo muito distinto do que outrora, motivou os filósofos da natureza em sua pesquisa do real.

As perguntas levantadas e os modos de respondê-las podem ter variado enormemente, mas a paixão por compreensão, a curiosidade intelectual, a atitude de investigação da natureza parece ser comum entre os físicos filósofos como Heisenberg e os velhos filósofos gregos. Desde os primeiros cosmólogos, os physikós pré-socráticos, o homem busca compreender a natureza, pressupondo sua ordem e unidade. Movidos por uma curiosidade intelectual inesgotável, não nos cansamos de questionar como pode haver algo ao invés do nada, e por que esse algo é como é e não de nenhuma outra maneira. Conforme Boltzmann é essa atitude filosófica que anima a pesquisa natural. A filosofia coloca aquelas questões mais básicas, sem as quais a pesquisa científica carece de sentido:

Qual é a definição de filosofia que se me impõe com uma força irresistível? Eu senti como um pesadelo opressor a sensação de que seria um enigma insolúvel a questão de como é possível que eu exista, a questão de como é possível que exista um mundo e a questão sobre o porquê desse mundo ser exatamente como é e não de alguma outra maneira. A ciência que conseguisse resolver esse enigma parecer-me-ia a maior, a verdadeira rainha das ciências, e eu a chamei de filosofia (BOLTZMANN. 2005, p. 25).

Neste trabalho chamamos de físicos filósofos um extenso grupo de cientistas da primeira metade do século $\mathrm{XX}$, cujos trabalhos foram pioneiros tanto no estabelecimento da teoria quântica, quanto da física relativística, e que faziam ciência e filosofia da ciência a um só tempo. Eram europeus, em sua maioria do mundo de língua alemã (alemães, austríacos), mas com 
exceções, destacando-se também britânicos, e franceses. Podemos citar como físicos filósofos, Planck, Einstein, Bohr, Heisenberg, Schrödinger, Weiszäcker, Born, Pauli, Eddington, James Jeans, Dirac, Louis de Broglie, dentre outros ${ }^{2}$. Fazer ciência, para os físicos filósofos, era participar dessa tradição de investigação filosófica de busca pela compreensão da realidade. Quando faziam perguntas específicas de um determinado campo científico, em último caso estavam perguntando "O que é a realidade?", "Quais são suas leis?", "Por que as coisas são como são?", "Como elas funcionam?", "A que mecanismos obedecem?". Pressupunham assim a ordem e a unidade da natureza, e a capacidade humana de entendê-la. Apartar a ciência da reflexão epistemológica, ontológica, lógica, ética, enfim, filosófica, seria um modo de empobrecê-la, e mesmo descaracterizá-la, retirando-lhe uma parte constitutiva essencial.

Heisenberg nos conta, em sua obra autobiográfica A Parte e o Todo a surpresa que um jovem físico norte-americano lhe causara em sua visita aos Estados Unidos. Enquanto que para um físico alemão de sua geração seria muito estranho fazer física sem filosofia, o jovem americano encarava a física como uma atividade prática não filosófica (HEISENBERG. 1996, p. 113). Parecia-lhe que o cientista que não reconhecesse a importância do pensamento filosófico para pesquisa científica estava, a um só tempo, demonstrando ignorância em relação à história de seu próprio campo de atividades e privando-se de compreender com maior profundidade as implicações de suas investigações. Para Heisenberg, portanto, filosofia e ciência formam uma unidade coerente e complementar. O cientista, portanto, não pode escolher entre fazer ou não filosofia, uma vez que sua atividade é intrinsecamente filosófica. $\mathrm{O}$ mesmo se dá com a história da ciência.

\section{Qual é o valor da ciência?}

Os físicos filósofos negavam uma perspectiva utilitarista ou instrumentalista que concebia a ciência como algo importante por fomentar o progresso material, a produção industrial e o desenvolvimento econômico.

\footnotetext{
${ }^{2}$ Tal classificação é sumamente arbitrária. Trata-se de um recorte que trabalha com os envolvidos com a teoria quântica e a física relativística no início do século XX. Uma compreensão mais ampla do termo "cientistas filósofos" deve abarcar investigadores anteriores, como Poincaré, Duhem, Boltzmann, Hertz, Mach, Ostwald, Kirchoff e assim por diante. Quando chegamos a um cenário anterior a 1833, quando o termo cientista foi cunhado por Whewell, ele mesmo um cientista filósofo, constatamos que todo homem de ciência era "filósofo natural", como o foram Galileu, Newton, Darwin e Laplace etc. Ou seja, o "cientista não filósofo" é um produto bastante recente na história da ciência, ao menos entre os europeus, que surge com mais força, sobretudo, na segunda metade de século XX.
} 
Tais elementos não seriam indesejáveis, mas também não seria aquilo que justifica e legitima a pesquisa científica. A ciência não necessita buscar sua legitimação fora de si mesma. A busca por conhecimento é um valor em si. Heisenberg sustenta que o valor da pesquisa científica não é utilitário, mas epistêmico:

Em todo caso, o valor de uma realização científica não é medido segundo o objeto, isto é, não é medido segundo a significação humana do material a ordenar, e, com maior razão, não segundo uma "utilidade prática" qualquer, mas apenas segundo a beleza e a força frutífera das estruturas expostas. [grifo nosso] (HEISENBERG. 2009, p. 130)

Schrödinger defende a mesma posição que Heisenberg. É pela importância filosófica, cultural, pela vitalidade intelectual, que devemos julgar o valor da ciência, e não por sua natureza estratégica para a satisfação de interesses econômicos e políticos. Schrödinger ataca o utilitarismo como um modo superficial de se compreender o que é a ciência e qual é a importância de seus resultados. Os homens práticos podem ter interesses utilitários na ciência, e com frequência buscam manipulá-la e servir-se dela como um instrumento para a promoção de seus interesses unilaterais, mas os cientistas não podem concordar com esta avaliação grosseira de seus trabalhos, e devem responder pelo valor da ciência apelando para sua importância epistêmica:

Qual é o valor da ciência? (...) Muitas pessoas, particularmente as que não estão profundamente interessadas na ciência, sentem-se inclinadas a responder a esta questão assinalando as consequências práticas dos progressos científicos na transformação da tecnologia, da indústria, da engenharia, etc., de fato, na alteração de toda a nossa forma de vida durante menos de dois séculos, com mudanças cada vez maiores e mais rápidas. Poucos cientistas concordam com esta apreciação utilitarista de seus esforços. (SCHRÖDINGER. 1996, p. 98).

Schrödinger pensa a ciência como parte da cultura, e portanto, seu valor é cultural. A ciência está inserida em uma tradição de investigação filosófica, movida, por sua vez, pelas grandes questões metafísicas.

Podem perguntar - têm de me perguntar agora: Qual é, então, na sua opinião, o valor da ciência natural? Respondo: o seu âmbito, objetivo e valor são os mesmos que os de qualquer outro ramo do conhecimento humano. Ou melhor, nenhum deles por si só, apenas a união de todos eles, tem qualquer âmbito ou valor e isso acontece muito simplesmente porque: representa obediência ao comando da divindade délfica, $\gamma \nu \omega \theta \mathrm{r}$

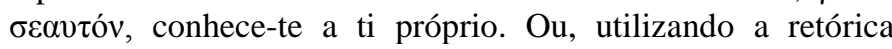
concisa e impressionante de Plotino (Enn. VI, 4, 14): "E nós, quem somos nós afinal?” (SCHRÖDINGER. 2003, p. 99) 
A questão posta por Plotino (204-270 d.C), pensador neoplatônico, "Quem somos nós?", ocuparia um lugar central na cultura. Entendemos que tal questão está interconectada a muitas outras questões básicas. Perguntar "quem somos nós" é perguntar o que é a realidade, por que existimos ao invés de não haver coisa alguma, qual nossa posição no universo, qual deve ser nosso lugar na Terra e como devemos nos relacionar com a natureza e uns com os outros, quem somos nós no sistema solar, na galáxia, no cosmos, quem somos nós para desintegrar o átomo e desvendar o DNA, como devem ser nossas cidades, roupas e alimentos, como e para que devemos estudar, nos educar, conhecer a natureza etc. De um modo ou outro, todos os campos da cultura participariam do esforço por responder todas as questões (inúmeras) que derivam daquela de Plotino, e nisso residiria a razão de ser da pesquisa científica:

(...) pretendia dizer que considero a ciência como uma parte integrante do nosso esforço para responder à grande questão filosófica que abarca todas as outras, a questão que Plotino expressou de forma breve: quem somos nós? E mais do que isso, considero que esta é não só uma das tarefas da ciência, mas $\boldsymbol{a}$ tarefa da ciência, a única que efetivamente tem importância. (SCHRÖDINGER. 2003, p. 99)

Se hoje poderia parecer anacrônico e ingênuo responder pelo valor da ciência afirmando que este reside no fato que a ciência é uma busca pela verdade e um fim em si mesmo, aos físicos filósofos do início do século XX, como Heisenberg e Schrödinger, ingênuo, e irresponsável, seria abdicar desta dimensão epistêmica da ciência em prol de um utilitarismo pautado por interesses econômicos. Também Bohr, assim como Schrödinger, pensava no valor cultural da ciência, e na impossibilidade de dissociação entre ciência e cultura:

Evidentemente, é impossível traçar uma distinção nítida entre a filosofia natural e a cultura humana. As ciências físicas, na verdade, são parte integrante de nossa civilização, não apenas pelo fato de nosso domínio cada vez maior das forças da natureza haver modificado tão completamente as condições materiais da vida, mas também porque o estudo dessas ciências contribuiu para esclarecer os antecedentes de nossa própria existência (BOHR. 1995, p. 30).

Ainda tratando a ciência como "filosofia natural", Bohr concebe sua íntima e inseparável relação com a cultura. A ciência pode alterar não somente a base material da vida, mas promover avanços em nossos conhecimentos existenciais. Se presa do utilitarismo, pode perder tanto sua dimensão filosófica, e deixar de promover material valioso para nossa reflexão existencial, como ser instrumentalizada por interesses unilaterais, 
colocando-se a serviço não do bem público e do bem estar social, mas dos objetivos estratégicos de certos grupos que agem sempre no sentido de aumentar o próprio lucro e concentrar poder.

\title{
Ciência e História
}

No século passado houve uma grande divergência entre historiadores da ciência acerca do problema da origem da ciência, ou da chamada revolução científica. O debate ocorreu entre "continuístas" (Como Crombie (Cf. Koyré. 1982, p. 59)) e "descontinuístas" (partidários da "Revolução" como Alexandre Koyré). Os continuístas defendiam que não havia ruptura entre as pesquisas naturais realizadas durante a idade média e a ciência moderna. Já os descontinuístas sustentavam a existência de uma revolução no campo das ideias. A ciência moderna teria dois traços distintivos em relação ao mundo medieval: (1) A destruição (da ideia antiga) do Cosmos, isto é, do modelo ptolomaico-aristotélico e (2) a geometrização do espaço (e consequentemente a matematização e a geometrização da ciência) (Cf. Koyré. 1982, pp. 154, 155). Para Koyré, a ciência moderna começa com o neoplatonismo de Galileu ao substituir o mundo fechado ptolomaico pelo universo aberto copernicano, e a física qualitativa aristotélica pela física matemática pitagórico-platônica (Cf. Koyré. 1982, p. 71).

A ciência deriva da filosofia? Desenvolve-se em paralelo? Nasce de um rompimento com esta? Para Heisenberg, a ciência representa uma continuação da filosofia. Heisenberg não situa o nascimento da ciência em Galileu, como o faria Koyré, mas nos gregos antigos. Nesse sentido Heisenberg foi um continuísta:

\begin{abstract}
As conquistas dos tempos modernos, de Newton e de seus sucessores, apareceram-me como continuação imediata da obra em que tinham trabalhado matemáticos e filósofos gregos; o desenvolvimento completo da ciência parecia-me um todo único, e não me passou pela cabeça a ideia de considerar a ciência e a técnica como um mundo radicalmente diferente do da filosofia de Pitágoras ou de Euclides. (HEISENBERG, 1962, p. 57).
\end{abstract}

Heisenberg, portanto, propõe uma interpretação da história da ciência, de acordo com a qual o nascimento da filosofia natural na Grécia antiga é, concomitantemente, o nascimento da investigação científica. O continuísmo de Heisenberg é bastante forte, pois traça uma linha claramente visível e sem rupturas, que liga a ciência atual à filosofia grega. Isto não é negar revoluções pontuais, ou mesmo grandes mudanças globais, mas defender que independente das transformações pelas quais a pesquisa científica passou ao longo dos séculos, algo permaneceu incólume, alguma coisa permanente e regular simplesmente não foi atingida, e tal coisa é estilo de pensamento e a atitude filosófica dos velhos gregos, que ainda animam 
os cientistas atuais. Também para Erwin Schrödinger, a origem da ciência moderna encontra-se não na Europa dos modernos, mas na Grécia dos antigos. Schrödinger identificará a origem da ciência com a origem da filosofia. Tales de Mileto, e os jônios de um modo geral, foram os primeiros cientistas:

O que é que aconteceu de tão extraordinário naquela época na história das ideias que faz com que designemos este acontecimento como o "Nascimento da Ciência" e com que falemos de Tales de Mileto como o primeiro cientista do mundo (Burnet)? A ideia grandiosa que estes homens transmitiram foi que o mundo à sua volta era algo que podia ser compreendido, se as pessoas se dessem ao trabalho de observar com atenção (...). Estes homens [Tales, Anaximandro e Anaximenes] libertaram-se da superstição e não pactuaram com nada disso. Encararam o mundo como um mecanismo bastante complicado, que agia de acordo com leis inatas e eternas, e que eles tinham curiosidade em descobrir. Esta, como é evidente, é a atitude fundamental da ciência até a atualidade [grifo nosso] (SCHRÖDINGER. 1996, p. 58).

A atitude filosófica que é fundamental à ciência, dos pensadores de Mileto aos dias atuais - conforme Schrödinger - é o abandono da superstição, a assunção de determinados pressupostos, como a ordenação do mundo em leis invariáveis e regulares, e a consideração de que o ser humano, unindo reflexão e observação, é capaz de compreender a natureza. Os filósofos jônios teriam todos os requisitos necessários para que alguém seja considerado um cientista, e deram os passos decisivos em direção ao estabelecimento da ciência. Para Schrödinger, o primeiro passo é a curiosidade. Quando tais homens trocaram a fé ingênua, supersticiosa e dogmática, pela curiosidade intelectual, começaram sua caminhada científica. $O$ primeiro requisito de um cientista é ser curioso (SCHRÖDINGER. 1996, p. 58). Para o físico filósofo austríaco, independente da adequação das respostas oferecidas para os problemas da origem e do funcionamento do universo, esse primeiro passo foi fundamental. O segundo passo, também dado por Tales, é o reconhecimento de que a complexidade e a diversidade podem ser geradas a partir de causas únicas e simples. Assim, toda a matéria que compõe o mundo, independente de sua variedade, deve ser uma forma diferente do mesmo elemento (SCHRÖDINGER. 1996, p. 59). A busca por ordem e unidade, portanto, foi o que fez com que aquela curiosidade não se perdesse, e fosse direcionada para um tipo de prática que hoje chamamos de pesquisa científica. O terceiro passo foi dado por Anaxímenes, discípulo de Anaximandro. Anaxímenes buscou uma síntese entre teoria e observação, e tentou a todo custo aplicar suas hipóteses a casos concretos, e essa foi uma grande conquista (SCHRÖDINGER. 1996, p. 61). Mas, para Schrödinger, não foi somente a atitude geral que anima a ciência que nasceu na Grécia. 
Determinados ramos muitos específicos da física também:

(...) a teoria quântica remonta há 24 séculos, a Leucipo e Demócrito. Eles inventaram a primeira descontinuidade átomos isolados implantados no espaço vazio. A nossa noção de partícula elementar descende historicamente da noção que eles tinham do átomo, e conceitualmente deriva também da sua noção do átomo. Nós limitamo-nos simplesmente a segui-la (SCHRÖDINGER, 1996, p. 134)

Aqueles que não consideram relevante a questão da relação entre filosofia e ciência argumentam que tal que a ciência moderna surge na Europa com a superação da filosofia natural. Para Schrödinger e Heisenberg, entretanto, não é somente correto dizermos que a ciência tem origem na filosofia grega como sustentarmos que tal relação é epistêmica e intrínseca. Assim como Schrödinger, Heisenberg desloca o nascimento da ciência para a antiguidade grega:

O grande rio da ciência, que atravessa a nossa época, brota de duas fontes situadas no terreno da antiga filosofia, e, embora mais tarde muitos outros afluentes tenham desaguado neste rio, contribuindo para engrossar o seu fecundo caudal, a sua origem é, não obstante, sempre claramente reconhecível. (HEISENBERG, 1962, p. 62)

As fontes que alimentam o rio da ciência e que estão aí, em nossa época, tão vivas hoje quanto o foram outrora, nasceram no terreno da filosofia grega antiga.

\section{Física Nuclear e Filosofia Grega}

A física nuclear nos remete à novidade. Trata-se de um dos últimos capítulos da história humana. Somos facilmente levados a conceber um mundo formado por pesquisas de ponta e de alta tecnologia e inovação. Já a Filosofia Grega nos transporta ao passado, a uma época distante nos rincões da antiguidade. Tais áreas poderão estar intimamente ligadas por pontes sólidas, ou até mesmo entrelaçadas de tal modo que seja possível identificar algumas interseções? Para Heisenberg o conhecimento histórico de um cientista é uma necessidade de trabalho, e não um hobby. Não é um indicativo raro de elevada erudição, mas um instrumento de pesquisa indispensável para prática científica cotidiana. Sendo assim, um físico nuclear não poderá dominar completamente seu campo de estudo caso careça de formação filosófica e histórica.

A Física Nuclear é um dos mais novos desenvolvimentos da ciência natural. Mas a concepção de estrutura atômica da matéria - de que existem partículas elementares, unidades 
indivisíveis, que são os blocos de construção de toda matéria foi sugerida há 2.500 anos pelos antigos filósofos gregos. Qualquer um que desejar compreender a teoria atômica moderna deverá estudar a história do conceito de átomo. (HEISENBERG, 1953, p. 5)

Se para Heisenberg o estudo do desenvolvimento filosófico do conceito de átomo na Grécia antiga é necessário para qualquer um que deseja compreender a física nuclear, então o físico não pode se limitar a ser um técnico; deve se posicionar como um pensador amplo, tal como outrora o fora o filósofo natural, alguém que se destaca em sua ciência específica, mas que também conhece profundamente filosofia e história, e que utiliza desse conhecimento para fazer a ciência da melhor forma possível. A compreensão do desenvolvimento histórico e filosófico do conceito de átomo se revelaria de grande importância para o entendimento dos fundamentos da física nuclear, mesmo de seus avanços mais recentes:

Para se adquirir uma compreensão dos fundamentos da física atômica nós devemos seguir, passo a passo, as ideias que, dois mil e meio anos atrás, conduziram a filosofia natural à teoria atômica, e devemos então encontrar uma conexão com essas ideias fundamentais, mesmo nos avanços mais modernos da física atômica. (HEISENBERG. 1952, p. 96)

Conforme Heisenberg, os gregos antigos desenvolveram alguns dos fundamentos epistêmicos da pesquisa científica. Heisenberg nos lembra de que duas teorias ou conjuntos de teorias filosóficas elaboradas na Grécia Antiga foram, e continuam sendo pilares da ciência: Por um lado, a matematização da natureza e a geometrização da física realizadas pelos pitagóricos e por Platão, e por outro, a teoria de que toda a complexa diversidade dos fenômenos naturais pode ser unificada, ordenada e deduzida de uma única causa natural simples, o átomo. A concepção filosófica atomista, portanto, permanece viva, na visão de Heisenberg, como um dos fundamentos da física, bem como o formalismo matemático de Pitágoras e de Platão, de acordo com o qual a estrutura do mundo físico é matemática, de modo que as matemáticas são instrumentos fecundos na dissecação das estruturas elementares da natureza, pois refletem alguma coisa acerca do próprio modo como a natureza se organiza por meio de regularidades, de um nomos, ou seja, de uma ordenação unificadora.

A ciência moderna tem seguido algumas tendências da filosofia natural grega, pois tem reconsiderado uma série de problemas com que a filosofia havia se debatido em seus inícios (...). Existem, especificamente, duas ideias da antiga filosofia grega que na atualidade ainda determinam o curso da ciência e que são, por essa razão, de especial interesse para nós: a convicção de que a matéria consiste de pequenas unidades indivisíveis, os átomos, e a crença na força das estruturas matemáticas. 
(HEISENBERG, 1952, p.53).

Heisenberg não diz que duas ideias filosóficas são influentes, importantes, ou interessantes para a pesquisa científica atual, mas que são "determinantes". Ora, se $\varphi$ é determinante para $\xi$, então, se não $\varphi, \operatorname{logo}$ não $\xi$. Conforme Heisenberg, tais ideias filosóficas determinaram o modo e os objetivos da ciência, desde seu nascimento, e ainda o fazem na atualidade. Heisenberg considerou a relação entre filosofia e ciência como sendo de fundamental importância para o aprofundamento de nossa compreensão, tanto da natureza, quanto da própria atividade científica. Veremos a seguir como Heisenberg e outros físicos filósofos pensaram que a imagem atomista de mundo, oriunda da metafísica materialista da antiguidade grega entrou em crise com a emergência da nova física no primeiro quarto do século XX.

\section{Física dos quanta e ontologia neoplatônica}

Apesar de pensar que o atomismo consolidou-se historicamente como uma das bases das ciências da natureza, Heisenberg concebera que a física dos quanta demandava uma profunda reformulação conceitual, exigindo, portanto, outra fundamentação metafísica. O conceito de átomo, por exemplo, já não poderia esgotar-se na concepção ordinária de matéria, uma vez que a própria matéria seria decorrente de princípios formais de simetria. Heisenberg, portanto, parece dar um passo neoplatônico e promover uma "matematização do átomo", ou, uma vez que o átomo da física moderna possui estrutura interna, uma "matematizção das partículas elementares". Não restam dúvidas de que Heisenberg considera as partículas elementares como entidades produzidas por princípios matemáticos fundamentais:

Sinto-me fascinado pela ideia de que a simetria seja algo muito mais fundamental do que a partícula em si. Isso se enquadra no espírito da teoria quântica, tal como Bohr sempre a concebeu. Também se enquadra na filosofia de Platão. (HEISENBERG. 1996, p. 193).

No pensamento de Bohr, o atomismo materialista dos antigos foi fundamental para o estabelecimento da ciência moderna, mas perdeu sua validade e significação com o aparecimento da teoria quântica, uma vez que essa impôs a necessidade de uma revisão conceitual profunda dos fundamentos da física. Mesmo que a velha linguagem comum à física clássica ainda tivesse que ser aplicada à teoria quântica, as velhas descrições, imagens e representações clássicas já não possuíam significado algum. A partícula subatômica, no escopo da teoria quântica, não se deixava capturar pelas velhas representações ordinárias:

(...) ficou cada vez mais claro que, para se obter uma explicação coerente dos fenômenos atômicos, era preciso

Teoria quântica, física nuclear e filosofia grega: ensaio sobre os físicos filósofos do século XX - Vinícius Carvalho da Silva 
renunciar ainda mais ao uso de imagens, e que era necessária uma reformulação radical de toda a descrição para abarcar todas as características que o quantum de ação acarretava (BOHR. 1996, p. 110).

Conforme Bohr, o conceito de partícula material tal como descrito na física clássica não era suficiente para explicar o quantum da nova física, portanto, as descrições passadas deveriam ser abandonadas em detrimento de novas abordagens cada vez mais abstratas. Na filosofia natural proposta por Heisenberg, a matéria é apenas o produto de relações matemáticas ontologicamente fundamentais. A matéria é observável, sensível, mensurável, mas tais relações matemáticas fundamentais são inobserváveis, exclusivamente inteligíveis e ideais. O platonismo fica evidente em tal construção. As partículas elementares podem ser detectadas por meio de chapas fotográficas, contadores Geiser, câmaras de nuvens ou aceleradores de partículas, mas os princípios matemáticos subjacentes são absolutamente abstratos, ou ideais, e podem ser representados somente por meio de equações e demais entidades formais. As entidades teóricas, matemáticas, portanto, não são meros recursos de pesquisa, construções intelectuais meramente especulativas, ou um determinado tipo de linguagem, mas entes reais, e fundamentais, que precedem, determinam e regulam os entes materiais.

Heisenberg escreveu um capitulo chamado "Física atômica e filosofia platônica" em A Parte e o Todo. Nele, o autor narra a forte impressão que o Timeu de Platão lhe causara desde a mocidade. Platão defende que o fundamento da realidade é um "mundo" abstrato de entes matemáticos. Platão não estaria defendendo que a natureza é constituída por aquelas determinadas formas geométricas, tetraedros, octaedros, mas enfim propondo uma geometrização da física. É possível não aceitar que os sólidos platônicos são as unidades ontológicas fundamentais, e ainda assim ficar com o que é fulcral no Timeu: a matematização do real. Tal matematização caminhou lado a lado com o velho atomismo, mas na física dos quanta deveria deixar de estar ao seu lado e passar a se encontrar em sua base:

Até então acreditávamos na antiga representação de Demócrito, que pode ser resumida por "no princípio era a partícula". Havíamos presumido que a matéria visível compunha-se de unidades menores; se continuássemos a dividir estas por tempo suficiente, chegaríamos às unidades mais diminutas, que Demócrito havia chamado de "átomos" e que os físicos modernos chamavam de "partículas elementares", por exemplo, prótons e nêutrons. Mas, talvez toda essa filosofia fosse falsa. (...) Talvez a matéria pudesse ser ainda mais dividida, até finalmente já não ser uma verdadeira divisão de uma partícula, e sim uma transformação de energia em matéria, até as partes já não serem menores do que o todo de que foram separadas. Mas o que haveria no início? Uma lei física, a 
matemática, a simetria? No início era a simetria! Isso soava como o Timeu de Platão (...). As partículas elementares incorporam simetrias; são suas representações mais simples e, no entanto, são apenas consequências delas. (HEISENBERG. 1996, p. 157-158)

Nessa linha de raciocínio, os átomos são de fato entidades da natureza, mas não são ontologicamente fundamentais. São fenômenos precedidos pelas bases matemáticas abstratas sem as quais o universo físico não seria como é. A questão que temos que colocar é se para Heisenberg, a física contemporânea resgataria o idealismo platônico como a metafísica mais viável para a ciência. A resposta deve ser claramente afirmativa:

(...) em Platão, no limite mais baixo das séries das estruturas materiais, não existe efetivamente algo material, mas uma forma matemática, se preferirdes, uma construção intelectual. A raiz última a partir da qual o mundo pode ser uniformemente inteligível é, segundo Platão, a simetria matemática, a imagem, a ideia; esse conceito é, portanto, denominado idealismo. (HEISENBERG. 2000, p. 12)

Evidentemente idealismo não significa mentalismo. A matéria não é produto da mente humana. A realidade dos entes matemáticos ideais é independente da mente humana. Apesar de dizer que, se preferirmos, poderemos pensar a "forma matemática" como uma "construção intelectual", Heisenberg concebe que a simetria matemática não é apenas uma invenção do espírito humano, mas algo fundamental. Neste sentido, a física atual seria platônica:

Independente da decisão última podemos afirmar agora que a resposta final estará mais próxima dos conceitos filosóficos expressos, por exemplo, no "Timeu" de Platão do que dos antigos materialistas (HEISENBERG. 2000, p. 26).

Heisenberg considerava que o momento no qual a física se encontrava desde o desenvolvimento da mecânica quântica era extraordinário e pela primeira vez na história da ciência natural a metafísica do materialismo atomista revelar-se-ia insuficiente para sustentar o quadro geral da física, devendo ser substituída por uma ontologia neoplatônica. A física contemporânea estaria repleta de "inobserváveis", daí, nas palavras de Caruso e Oguri, muitos cientistas desde Heisenberg, como Murray GellMann, desvencilharam-se da filosofia materialista e assumiram posições filosóficas formalistas (neoplatônicas):

Partículas observadas diretamente na natureza, como o próton e o nêutron, e outras, produzidas em laboratório, seriam constituídas de partículas não-observáveis, cujas existências teriam origem em princípios formais de simetria, portanto, em 
princípios puramente matemáticos. Com relação a essa ideia de Gell-Mann que, aliás, se mostrou muito frutífera, pode-se referir às palavras de Heisenberg: Nossas partículas elementares são comparáveis aos corpos regulares do Timeu de Platão. São os modelos originais, a ideia de matéria. (CARUSO; OGURI. 2006, p. 570)

A tese de que o conceito ordinário de matéria era insuficiente no escopo da física dos quanta não se limitou a Heisenberg. Louis de Broglie, em $O$ Futuro da Física também considerou a filosofia materialista como uma concepção de mundo simplória em face dos avanços empreendidos pela física contemporânea. Broglie defendera que o materialismo como ontologia não passa de uma suposição dogmática decorrente da falta de investigações analíticas acerca dos conceitos fundamentais da física:

De fato, muitas vezes, por não terem analisado suficientemente os conceitos e os métodos de que se servem, certos sábios aceitam, inconscientemente e sem discussão, certo sistema filosófico, e tornam-se de tal modo dogmáticos que não submetem a nenhuma crítica as suas ideias preconcebidas. (BROGLIE. 1955, p. 34)

Tal dogmatismo, de acordo com Broglie, está na base da metafísica materialista. Para o cientista francês, a mecânica quântica revelou "uma realidade muito mais profunda", que permanecia encoberta no quadro geral da física clássica (BROGLIE. 1955, p. 35). O materialismo, portanto, é superficial:

(...) certos sábios dos tempos modernos, vítimas dum ingênuo realismo, adotaram, quase sem se aperceberem disto, uma metafísica de caráter materialista e mecanicista, e consideraram-na como a expressão da própria verdade científica. Um dos grandes serviços prestados ao pensamento contemporâneo pela evolução da recente Física é ter feito ruir essa metafísica simplista é ter conseguido chamar a atenção para certos problemas filosóficos tradicionais vistos agora sob aspectos inteiramente novos. (BROGLIE. 1955, p. 34)

Erwin Schrödinger também questionou, em diversas oportunidades, a antiga imagem da Physis centrada na metafísica materialista do antigo atomismo grego, indagando se as concepções antigas de matéria e realidade ainda faziam sentido no escopo ontológico e epistemológico da mecânica quântica. Em A Natureza e os Gregos chega a declarar que

$\mathrm{O}$ atomismo tem se mostrado ser infinitamente fértil. Contudo, quanto mais se pensa nele, mais temos que nos perguntar até que ponto é uma teoria verdadeira. Será que se alicerça exclusivamente sobre a estrutura objetiva e efetiva do "mundo real à nossa volta?" Será que não é, de alguma forma 
significativa, condicionado pela natureza da compreensão humana - que Kant designou por "a priori"? (SCHRÖDINGER. 1996, p. 82)

Schrödinger demonstra sua desconfiança em relação ao materialismo novamente em A nossa imagem da matéria quando conclui que essa imagem da realidade material é hoje mais vaga e incerta do que foi por muito tempo (SCHRÖDINGER. 1996, p. 46). O que podemos tomar como matéria? O que é a matéria? Uma substância? Um substrato?

O que são de fato essas partículas, esses átomos, essas moléculas? (...) Eles podem talvez no máximo ser pensados como criações mais ou menos temporárias dentro do campo de ondas, cuja estrutura e variedade estrutural, no sentido mais amplo do termo, são agudamente determinados por meio das leis de onda na medida em que reaparecem sempre do mesmo modo, que devem ocorrer como se fossem uma realidade material permanente. (SCHRÖDINGER. 2000, p. 66)

Eis aqui um interessante ponto de encontro entre ideias vindas de diferentes direções. Heisenberg pensa a matéria como efeito de algo mais fundamental, a simetria matemática. Schrödinger, por sua vez, parece deslocar o conceito de matéria de uma região central para uma periférica, concebendo que a matéria pode ser pensada, no máximo, como criações mais ou menos temporárias dentro do campo de ondas. Também na física relativística, com Einstein, a partícula material sofrerá uma espécie de rebaixamento ontológico, passando a ser secundária em relação aos conceitos de energia e campo (SILVA. 2001, p. 118).

Uma das primeiras formulações de um "princípio de conservação" se deve a Heráclito. Ao defender que o fogo é o princípio organizador do mundo, que promove a transformação de todas as coisas, Heráclito admite que tudo está em movimento e mutação, mas existe ao menos algo que é regular e permanente. Este algo não é uma substância, mas uma "lei de transformação contínua". Popper, em $O$ mundo de Parmênides defende tese contrária. Conforme Popper, o atomismo foi numa solução física para a cosmologia do universo maciço de Parmênides. Os atomistas preservaram a teoria da imutabilidade do Ser ao conceber que os átomos são indestrutíveis, indivisíveis e imutáveis. O que muda são os arranjos atômicos no espaço. Deste modo, teríamos aí um princípio de conservação da matéria em sua unidade elementar, o átomo, e poderíamos unificar a cosmologia de Parmênides com teorias físicas da mudança:

Tal teoria da mudança - de que toda mudança é movimento teoria de autoria de Leucipo e Demócrito - continuou sendo a base da física teórica por mais de dois mil anos, sobretudo mas de modo algum exclusivamente - sob essa forma, o racionalismo de Parmênides não só sobreviveu, como 
continuou a dominar a ciência ocidental. E ainda domina (POPPER. 2014, p. 195).

Seja como for, se Heráclito ou Parmênides responderam primeiro pelo que é regular e permanente na natureza, a resposta que Popper pensa ainda dominar a física recebeu muitas e severas críticas de físicos filósofos como Heisenberg e Schrödinger. Este último discordou diretamente da solução atomista. O que é regular no mundo natural não é a matéria, porque nem no caso da partícula elementar a matéria é pensada como permanente. O que é regular é a forma pela qual tal matéria se organiza. Para Schrödinger, a ideia de matéria como substância ou substrato, coisa concreta e permanente, não tinha lugar na física dos quanta, não ao menos como conceito central. É o campo de ondas que é regular, as partículas de matéria são eventos que ocorrem conforme as possibilidades do campo (SILVA. 2011, p.116).

\section{Conclusão}

Podemos notar um ponto em comum nos pensamentos de Heisenberg, Schrödinger, Einstein e Broglie; - e poderíamos estender nosso raciocínio a Bohr, Pauli e outros físicos filósofos - não seria possível admitir uma continuidade linear ligando o conceito de matéria tal como historicamente consolidado desde os atomistas antigos às partículas elementares da física dos quanta. Rupturas, tensões, deslocamentos e ressignifcações pareciam inescapáveis. Se havia uma continuidade entre a filosofia grega e a nova física no que diz respeito a atitude fundamental e aos pressupostos metafísicos básicos, a saber - a busca por compreensão da natureza centrada na ideia de que o mundo possui ordem, unidade, e pode ser conhecido - já com relação especificamente ao conceito atomista de matéria, a descontinuidade era patente. De um modo geral, os físicos filósofos também concordam quando respondem a questão do valor da ciência. Não negam sua importância prática para a vida material, o progresso econômico e o desenvolvimento industrial. Não opõem ciência, tecnologia e técnica. Mas nem por isso flertam com o utilitarismo reducionista que toma a ciência como uma ferramenta ou instrumento, ou seja, um meio para outros fins. Para os físicos filósofos, a ciência deve estar centrada em valores epistêmicos, e ser socialmente robusta, sendo um fim em si mesmo, afinal, a busca por compreensão do mundo não é uma arma, ou uma estratégia de mercado, mas uma necessidade humana básica e profunda. A perda do valor epistêmico e cultural da ciência poderia apontar também para a perda do sentido da civilização, o niilismo, a vulgarização do espírito e a banalização da cultura. Sendo assim, o valor da ciência, por mais que essa fosse um empreendimento histórico e social realizado por homens 
e mulheres de carne e osso seria intangível e sublime. Que assim seja. 


\section{Referências bibliográficas}

BOHR, N. Física atômica e conhecimento humano: ensaios 1932-1957. Trad. Vera Ribeiro. Rio de Janeiro: Contraponto, 1995.

BORN, M; AUGER; SCHRÖDINGER, E; HEISENBERG, W. Problemas da Física Moderna. Trad. Gita. K. Guinsburg. São Paulo: Perspectiva: 2006. BROGLIE, L. O Futuro da Física in Para Além da Ciência. Trad. Eduardo Pinheiro. Porto: Livraria Tavares Martins, 1955.

CARUSO, F \& OGURI, V. Física moderna: origens clássicas e fundamentos quânticos. Rio de Janeiro: Editora Campus, 2006.

CHIBENI, S. (Certezas e incertezas sobre as relações de Heisenberg). Rev. Bras. Ensino Fís. vol.27 no.2 São Paulo Apr./June 2005.

EINSTEIN, A. A Teoria da Relatividade Especial e Geral. Rio de Janeiro:

Contraponto, 2012.

Como eu vejo o mundo. Trad. H. P. de Andrade. Rio de Janeiro:

Nova Fronteira, 1981.

Escritos da maturidade. Trad. Maria Luiza X. de A Borges. Rio de

Janairo: Nova Fronteira, 1994.

Notas autobiográficas. Rio de Janeiro: Nova Fronteira, 1982.

. Sobre a teoria geral da gravitação: in Prêmios Nobel na Scientific

American. São Paulo: Duetto, 2010.

EINSTEIN, A; INFELD, L. A Evolução da Física. Trad. Giasone Rebuá. Rio de Janeiro: Zahar Editores, 1980.

HEISENBERG, W. A Imagem da Natureza na Física Moderna. Lisboa: Livros do Brasil, 1981.

A ordenação da realidade: 1942. Tradução de Marco Antônio

Casanova. Rio de Janeiro: Forense Universitária, 2009.

A parte e o todo: encontros e conversas sobre física, filosofia,

religião e política. Rio de Janeiro: Contraponto, 1996.

1987.

Física e filosofia. Brasília: Editora da Universidade de Brasília,

Más Allá de La Física. Madri: Editorial Católica, S. A., 1974.

Nuclear Physics. London: Methuen \& CO. LTD.,1953.

Páginas de reflexão e auto-retrato. Lisboa: Gradiva, 1990.

Philosophic problems of nuclear science. New York: Philosophical

Library, 1952.

KOYRÉ, A. Estudos Galilaicos. Lisboa: Publicações Dom Quixote, 1986.

KOYRÉ, A. Do espaço fechado ao universo infinito. Rio de Janeiro: Forense Universitária, 2006.

Estudos de História do Pensamento Científico. Rio de

Janeiro:Forense - Universitária, Brasília: Ed. Unb, 1982

KUHN, T. A estrutura das revoluções científicas. São Paulo: Editora Perspectiva, 2001.

LEITE, A; SIMON, S. (Werner Heisenberg e a Interpretação de 
Copenhague: a filosofia platônica e a consolidação da teoria quântica). Sci. stud. vol.8 no.2 São Paulo Apr./June 2010.

PIZA, A. Schrödinger e Heisenberg: A física além do senso comum. São Paulo: Editora Odysseus, 2007.

POPPER, K. O mundo de Parmênides: Ensaios sobre o iluminismo présocrático. Roberto Leal Ferreira (Trad.). São Paulo: Editora Unesp, 2014.

SCHEIBE, E. Die philosophie der physiker. München: Beck'schen Reihe, 2007.

SCHRÖDINGER, E. A Natureza e os Gregos: seguido de Ciência $e$ humanismo. Lisboa: Edições 70, 1996.

WEIZSÄCKER, C. La importancia de La ciencia. Barcelona: Editorial Labor, S, A., 1972.

SILVA, V. C. O anti-realismo na filosofia da física de Werner Heisenberg: da potentia aristotélica ao formalismo puro. Griot, v. 3,n2, p. 109-120, 2011.

Autor(a) para correspondência: Vinícius Carvalho da Silva, Universidade do Estado do Rio de Janeiro, R. São Francisco Xavier, 524, Maracanã, CEP 20550-900, Rio de Janeiro RJ, Brasil. viniciusphilo.uerj@gmail.com 